\title{
Population-based approaches to understanding disparities in cardiovascular disease risk in the United States
}

This article was published in the following Dove Press journal:

International Journal of General Medicine

7 August 2014

Number of times this article has been viewed

\author{
Garth Graham \\ Department of Medicine, University \\ of Florida, Gainesville, FL, USA
}

\begin{abstract}
This is a comprehensive narrative review of the literature on the current science and evidence of population-level differences in risk factors for heart disease among different racial and ethnic population in the US. It begins by discussing the importance of populationlevel risk assessment of heart disease in light of the growth rate of specific minority populations in the US. It describes the population-level dynamics for racial and ethnic minorities: a higher overall prevalence of risk factors for coronary artery disease that are unrecognized and therefore not treated, which increases their likelihood of experiencing adverse outcomes and, therefore, potentially higher morbidity and mortality. It discusses the rate of acute coronary syndrome (ACS) in minority communities. Minority patients with ACS are at greater risk of myocardial infarction, rehospitalization, and death from ACS. They also are less likely than nonminority patients to receive potentially beneficial treatments such as angiography or percutaneous coronary intervention. This paper looks at the data surrounding the increased rate of congestive heart failure in racial and ethnic minorities, where the risk is related to the prevalence of comorbidities with hypertension or diabetes mellitus, which, in combination with environmental factors, may largely explain congestive heart failure disparity. The conclusion is it is essential that health care providers understand these various communities, including nuances in disease presentation, risk factors, and treatment among different racial and ethnic groups. Awareness of these communities' attributes as well as differences in incidence, risk factor burdens, prognosis, and treatment are necessary to mitigate racial and ethnic disparities in heart disease.
\end{abstract}

Keywords: heart disease, health disparities, hypertension, acute coronary syndrome

\section{Introduction}

A large body of literature has come together to form a vision of a different future for cardiovascular risk in the US. Ongoing shifts in population demographics, combined with growing, well-established health disparities have changed the dynamics of population-level cardiovascular risk in the US. In the next 35 years, it is predicted that non-Hispanic whites will no longer comprise the majority of the US population due to increased numbers of Hispanics and Asians. ${ }^{1}$ There are well-established disparities in cardiovascular health outcomes between minority and nonminority groups across the US. Understanding varied risk factor profiles and how to treat a changing population are critical to achieving continued improvements in care. Such efforts will be key to eliminating racial and ethnic disparities in health and essential to improving population-level cardiovascular care.
Department of Medicine, University of Florida, PO Box 100277, Gainesville, FL 326।0-0277, USA

Email Garth.Graham@medicine.ufl.edu 


\section{Understanding health disparities in cardiovascular care}

Health disparities in the US exist by ethnicity, race, geography, and socioeconomic status. The overall cost of these disparities in the US has been estimated at around 1.24 trillion US dollars (Table 1). The US Office of Management and Budget has classified minority groups in the US as African American, Asian American and Pacific Islander, Native American, white, and Hispanic. ${ }^{1}$ Patient, provider, and system-related factors all contribute to racial and ethnic health disparities. At the patient level, individual behaviors (including diet and exercise) and potentially genetic factors may contribute to health disparities. At the provider level, factors can include unintentional bias and varying sensitivity to the needs and differences of patients from various backgrounds. At the health systems level, specific factors can include access to care, insurance coverage, cultural competency, and the kinds of infrastructure required to address the needs of diverse clients.

Unfortunately, there may not be adequate recognition of the issue among doctors; a large majority of physicians are unlikely to recognize disparities in their own hospital setting or within their own practices. ${ }^{2}$ Physicians are more likely to attribute disparity to patient-level or system-level deficiencies than to problems at the provider level. Awareness of potential disparities among clinicians is particularly important because there is a clustering of risk factors that is apparent in minority populations with coronary artery disease (CAD). ${ }^{3-5}$ Systematically identifying and treating modifiable cardiovascular disease (CVD) risk factors is critical to patients in these populations. As noted by Kurian and Cardarelli,

Better understanding and awareness of the disparities of CVD risk factors by race and ethnicity may help clinicians and public health professionals develop culturally

Table I Economic burden of health disparities in the United States

\begin{tabular}{ll}
\hline & Impact \\
\hline $\begin{array}{ll}\text { Combined costs of health inequalities and premature } & \text { \$I.24 trillion } \\
\text { (USD) }\end{array}$ \\
$\begin{array}{ll}\text { Peath } & \text { \$I trillion } \\
\text { with illness and premature death if minority health } & \text { (USD) }\end{array}$ \\
$\begin{array}{l}\text { inequalities were eliminated } \\
\text { Potential reduction in direct medical care expenditures }\end{array}$ & $\$ 229.4$ billion \\
if minority health disparities were eliminated & (USD) \\
Percent excess direct medical care expenditures for & $30.6 \%$ \\
African Americans, Asians, and Hispanics that were due & \\
to health inequalities & \\
\hline
\end{tabular}

Note: Reprinted with permission from LaVeist TA, Gaskin DJ, Richard P. The Economic Burden of Health Inequalities in the United States, 2009. Report commissioned by the Joint Center for Political and Economic Studies. ${ }^{59}$ Abbreviation: USD, US dollar. sensitive interventions, prevention programs, and services specifically targeted toward risk burdens in each of these populations. ${ }^{6}$

This review will look at identifying the varied cardiovascular risk profile among African Americans and Hispanic and Asian Americans in the US. By identifying these differences, they may be better identified and treated, which may lead to the reduction of health disparities.

\section{CVD risk in African American communities}

Disproportionate rates of CVD are seen in the US African American population. African American subgroups have a greater burden of myocardial infarction (MI), heart failure, stroke, and other cardiovascular events (Table 2). ${ }^{7}$ On a population level, there is a higher overall prevalence of risk factors that are unrecognized and therefore not treated, which places these individuals at a greater likelihood of experiencing adverse outcomes and therefore potentially higher morbidity and mortality. ${ }^{6,8}$ Among the various minority population groups, African American men have the highest overall death rate from CVD. ${ }^{8-10}$ This extends to African American females, whose death rates from CVD are higher than those of white females. ${ }^{9}$ Equally as concerning is the fact that deaths also occur much earlier in African Americans compared to whites. ${ }^{10}$

African American adults have among the highest rates of hypertension in the world. ${ }^{6,8,11}$ They and Mexican Americans tend to have higher blood pressure and exhibit lower levels of blood pressure control than whites in the US, even after consideration of modifiable health behaviors, suggesting that other racial/ethnic differences underlie these disparities. ${ }^{12}$

Studies assessing unique characteristics of high blood pressure in African Americans have found that aldosterone correlates significantly with several CVD risk factors associated with obesity-related high blood pressure in this population. ${ }^{13}$ Aside from being an independent marker for heart disease morbidity and mortality ${ }^{14} \mathrm{~N}$-terminal prohormone brain-type natriuretic peptide has been shown to be an independent biomarker for predicting events related to heart disease, including heart failure and overall mortality, in African Americans with kidney disease and high blood pressure. ${ }^{15}$ The pathologic developments accompanying risk factor aggregation contribute to a higher burden of disease among African American men and women. Unfortunately, despite having a higher risk burden, African American men and women are less likely to receive 
Table 2 Differentials in the prevalence of cardiovascular conditions across racial and ethnic groups

\begin{tabular}{|c|c|c|c|c|c|}
\hline Condition & White & $\begin{array}{l}\text { African } \\
\text { American }\end{array}$ & $\begin{array}{l}\text { Mexican American/ } \\
\text { Hispanic }\end{array}$ & $\begin{array}{l}\text { Native } \\
\text { American }\end{array}$ & $\begin{array}{l}\text { Asian Pacific } \\
\text { Islander }\end{array}$ \\
\hline Cardiovascular disease, myocardial infarction or angina, $\%$ & 6.2 & 6.2 & 6.9 & 11.2 & 4.7 \\
\hline Coronary heart disease $>20$ years of age $(M / F), \%$ & $9.4 / 6.0$ & 7.1/7.8 & $5.6 / 5.3$ & $7.6(18+)$ & $4.2(18+)$ \\
\hline Subclinical coronary artery calcification, $\%$ & $70 / 45$ & $52 / 37$ & $57 / 35$ & $59 / 42$ & - \\
\hline Congestive heart failure (M/F), \% & $2.8 / 2.1$ & $2.7 / 3.3$ & $2.1 / 1.9$ & - & - \\
\hline Stroke, years of potential life lost from stroke before age 75 & 173.7 & 475.3 & 195.5 & 202.6 & 187.4 \\
\hline Peripheral arterial disease in diabetes, $\%$ & 8.5 & 9.5 & 5.0 & - & 6.4 \\
\hline ESRD incidence (age- and sex-adjusted rates), per million & 262 & 1,009 & - & 537 & 364 \\
\hline Sudden cardiac death $(M / F)$, per 100,000 & $205 / 138$ & $207 / 141$ & $119 / 147$ & $133 / 77$ & $112 / 67$ \\
\hline Premature ( $<65$ years of age) cardiovascular mortality, & 14.7 & 31.5 & 23.5 & 36.0 & 21.1 \\
\hline
\end{tabular}

$\%$ of deaths from heart disease

Note: Copyright (C 2007 by SAGE Publications. Reprinted by permission of SAGE Publications from Davis AM, Vinci LM, Okwuosa TM, Chase AR, Huang ES. Cardiovascular health disparities: a systematic review of health care interventions. Med Care Res Rev. 2007;64(5 Suppl):29S-100S. ${ }^{60}$

Abbreviations: ESRD, end stage renal disease; F, female; M, male.

adequate treatment or achieve adequate control of these risk factors, including obesity or hypertension. ${ }^{4}$

African American patients are more likely to have symptoms and functional impairment from acute coronary syndrome (ACS) ${ }^{16}$ A significantly higher prevalence of coronary heart disease (CHD) has been identified in elderly African American women. ${ }^{17}$ Presentation of symptoms can vary as well. In a study of women with CHD, nearly all minority participants reported a higher sense of fatigue and sleep disturbance as prodromal symptoms, yet fewer than $50 \%$ reported prodromal chest pain or discomfort. ${ }^{18}$ The most commonly identified acute symptom was shortness of breath, with minority women reporting significantly more acute symptoms than white women. In another study of women, African Americans demonstrated the highest risk burden, whereas Hispanic and Alaska Native participants showed the least CVD. ${ }^{19}$ Individual and community characteristics explained some racial/ethnic disparities, but other disparities persisted even after controlling for these factors. ${ }^{19}$ Differences exist between the sexes in minority populations as well; men are more likely to be hospitalized for heart disease and acute MI, while women are more likely to be admitted for congestive heart failure (CHF) and stroke. ${ }^{8}$

The death rate from ACS is $30 \%$ higher among African Americans than in non-Hispanic whites. ${ }^{3}$ Patients from racial/ ethnic minority groups are generally younger, have another comorbidity (eg, hypertension, diabetes, obesity), and are more likely to be women. ${ }^{3,5,20}$ Minority patients with ACS are at greater risk of MI, rehospitalization, as well as death from ACS and are less likely to receive potentially beneficial treatments such as angiography or percutaneous coronary intervention than nonminority patients. ${ }^{7}$ Population-level data showed that among African American, Hispanic, and Asian patients who underwent percutaneous coronary intervention, only African Americans had a significant reduction in eventfree survival 2-years postprocedure. ${ }^{21}$ It is also noted that African Americans with acute MI are younger and are less likely to receive evidenced-based treatments. ${ }^{7}$ The decreased likelihood of undergoing appropriate treatment, compounded by decreased access to care, may exacerbate disparities in acute MI care. $^{22}$

African Americans are at a significantly higher risk of suffering from heart failure compared with other ethnic groups. ${ }^{23}$ Among CHF patients, African Americans were least affected by interim MI, while Hispanic and white participants were most affected by left ventricular mass increase. ${ }^{23}$ Risk was related to the prevalence of comorbidities with hypertension or diabetes mellitus, which, in combination with environmental factors, may largely explain CHF disparity. Adjustment for interim infarction accentuates ethnic differences in the incidence of CHF between African Americans and whites. Differential use of coronary revascularization may contribute to the poorer functional outcomes observed among African American patients with documented coronary disease and heart failure. ${ }^{16}$

In one study of largely African Americans with heart failure or left ventricular hypertrophy, those with heart failure shared many abnormalities of systolic, diastolic, and vascular functions with nonfailing left ventricular hypertrophy patients, but had accentuated left ventricular hypertrophy and left atrial dilation or failure. The emergence of data from studies such as the African-American Heart Failure Trial indicates that differences in pharmacology may require tailored drug treatment strategies for people of different racial/ ethnic backgrounds with heart failure. ${ }^{24}$ Drugs like isosorbide dinitrate/hydralazine hydrochloride (FDC I/H) significantly decreased the risk of all-cause death and first hospitalization for heart failure and improved quality of life, leading to the 
approval of the first drug tailored for specific racial/ethnic populations. ${ }^{25}$ African American patients with heart failure who were taking FDC $\mathrm{I} / \mathrm{H}$ and neurohormonal blockers showed significantly reduced mortality and improvement in event-free survival and hospitalization. ${ }^{25}$ These factors may help to clarify pathophysiology and better define the African American heart failure population. ${ }^{26}$

African Americans have the highest incidence of stroke among groups in the US; their strokes tend to be more severe with a higher morbidity and result in higher mortality. ${ }^{27}$ Similar to ACS, African Americans tend to be younger at the time of the first stroke event. Although the overall incidence of stroke in the US appeared to go down in 2010, the change was the result of a decrease in ischemic stroke in whites only; the incidence for African Americans remained unchanged. ${ }^{28}$

The high risk factor burden has been implicated as a factor in the higher stroke incidence, particularly the presence of hypertension or diabetes, and especially for African Americans. ${ }^{7,28}$ In one study, African Americans had a higher prevalence of five risk factors independently associated with stroke (treated diabetes, hypertension, peripheral vascular disease, higher C-reactive protein [CRP], and inactivity), whereas whites had a higher prevalence of three risk factors (older age, prior MI, and lower high-density lipoprotein [HDL] cholesterol). ${ }^{29}$

Awareness of stroke symptoms is suboptimal among minority women, even though they are at higher risk than nonminority women. ${ }^{30}$ One study noted that African Americans with hypertension may have been more aware of their disease status compared to whites, but were less likely to be adequately treated and subsequently have their disease under control. ${ }^{31}$ This may contribute significantly to the higher incidence of stroke in African Americans and should represent a treatment priority in terms of population management.

\section{CVD risk in Hispanic communities}

Unique among minority groups are Hispanic subpopulations, which are linked not just by geographic origin but also by common linguistics, with ancestry related to Spanish-speaking nations from Europe, Central and South America, and the Caribbean. Hence subgroup analysis, such as comparing Mexican American with Puerto Rican American, may be particularly valid for understanding health outcomes. Hispanics have been reported to have higher rates of CVD risk factors yet demonstrate lower rates of CHD and total CVD. ${ }^{8,32,33}$ A difference in risk factors and either prevalence of CVD or subclinical disease have also been seen in Mexican Americans, though their risk profiles were unique compared to individuals of other Hispanic backgrounds, indicating that it is important to delineate Hispanic subgroups. ${ }^{34}$

Elevated body mass index (BMI), ranging from obesity to being overweight, has a negative impact on all ages, racial and ethnic groups, and sexes. ${ }^{6,9}$ Diet and exercise, as evidenced by caloric management through proper nutrition as well as the recommended physical activity, also appears to be universally important to health. BMI and waist circumference are inversely associated with fitness, with low fitness most significant in African Americans and Mexican Americans. ${ }^{6,35}$ For more clearly defined populationlevel risk factors, the data around obesity remains among the most compelling, with very high rates seen in the US, particularly among Hispanic American subgroups, including Mexican Americans. Up to $75 \%$ of Mexican American men and $72 \%$ of Mexican American women are obese or overweight.

When looking at risk factors such as diabetes, the prevalence of diagnosed diabetes in subgroups such as Mexican-Americans and Puerto Ricans was over twice that of non-Hispanic whites. ${ }^{14}$ Outside of the environmental impact of lifestyle and behavior on the incidence and prevalence of diabetes in US Hispanics, data from 42 extended Mexican American families in San Antonio, Texas, showed that genes accounted for $30 \%$ to $45 \%$ of the phenotypic prevalence of diabetes. In fact, genes accounted for $15 \%$ to $30 \%$ of the phenotypic variation in measures of glucose, high blood pressure, and adiposity. ${ }^{36}$ Part of this was due to the unique admixture of US Hispanic populations, where a higher degree of Native American admixture served as a significant ingredient in the higher rates of type 2 diabetes, with a partial contribution of Spanish admixture to diabetes susceptibility among Mexico-originating populations.

Tremendous geographic variation in diabetes manifestation is seen between these populations in the Southeastern and Southwestern US, respectively, yet no differences among racial/ethnic minority populations were consistently found for many traditional risk factors. ${ }^{6}$ Certain patterns in dyslipidemia have been noted among Hispanic populations, with Hispanics overall having higher triglyceride levels and lower levels of HDL. ${ }^{34}$ There are subgroup differences, with Mexican Americans displaying dyslipidemia patterns seen in diabetics with more elevated small, dense, low-density lipoprotein particles. ${ }^{37}$ In looking at other nontraditional risk factors, some data suggest that coronary artery calcium is present in lesser amounts in Hispanics compared to whites. ${ }^{38,39}$ The exact impact of this difference in coronary calcium is not well known. 
In looking at high blood pressure, subgroups such as Mexican Americans continue to have a higher prevalence of hypertension and prehypertension that non-Hispanic whites. Puerto Rican Americans had the highest hypertension-related death rates compared to the other Hispanic subgroups, while those of Cuban heritage had the lowest overall hypertensionrelated death rates. An increase in CVD risk factors, specifically hypertension, between first- and second-generation Mexican Americans suggests that acculturation in terms of diet and lifestyle changes are negatively affecting CVD health in this population. ${ }^{40}$

There is a lack of data in terms of large studies on heart failure as it relates to US Hispanic populations. Still, it is believed that the rate of heart failure for Hispanics is lower than for African Americans but higher than for non-Hispanic whites. ${ }^{32}$ The etiology of heart failure is related not just to hypertension and $\mathrm{CAD}$; there are also data to show that metabolic syndrome and insulin resistance play a more significant role in the pathogenesis of heart failure in US Hispanics. Mexican Americans have the highest rate of age-adjusted prevalence of metabolic syndrome compared to other race/ ethnic groups. ${ }^{41}$ Metabolic syndrome has been linked to higher left ventricular mass and dysfunction, independent of blood pressure or underlying CAD. ${ }^{42}$ This may in part explain the differential prevalence and presentation of heart failure among Hispanics.

Looking at population-level data, Hispanics in the US undergoing coronary artery bypass graft surgery are generally younger, more likely to be women, and maintain a lower BMI. ${ }^{20,43}$ One study concludes that some easily measured characteristics can be used to make decisions about allocating resources to case management of Hispanic patients with heart disease. ${ }^{44}$ Such case management strategies might emphasize patient education, provider education, decision support, self-management, and in-person care management. These strategies should be considered to reduce disparities in ACS in this population.

\section{CVD risk in Asian American communities}

There are limited data available on CVD risk factors for Asian American subgroups, but traditional CVD risk factors in Asian Americans have similarities to whites in some instances. ${ }^{45,46}$ Judging by available data, the prevalence of CVD risk factors appears to vary greatly across the Asian subgroups, which could affect risk assessment. ${ }^{46}$ For example, it has been noted that South Asians may exhibit more nontraditional CVD risk factors, including differences in inflam- matory markers as well as insulin resistance. ${ }^{47}$ This is noted as well in other populations where markers such as levels of CRP vary among racial and ethnic groups. However, despite the ongoing discussions regarding the clinical impact of CRP, the meaning behind these differences and how to manage them remain ill defined. ${ }^{42,48}$

Across all minority populations there have been differences in access to screening programs for heart disease; for example, women and South Asians were less likely to undergo systematic screening than white males. ${ }^{49}$ It has been challenging to appropriately estimate risk in a variety of Asian American subgroups due to the lack of data and systematic studies. Unfortunately, traditional risk-assessment tools may not be entirely effective; for example, Framingham Risk has been demonstrated to systematically overestimate the risk of CAD in subgroups like Japanese Americans. ${ }^{50}$ By contrast, one study of 4,497 South Asians has suggested that adding 10 years to the age of South Asian people was the simplest way of calculating coronary heart disease risk using paper-based methods. ${ }^{51}$ Given the overall challenges with traditional risk factors and risk factor tools in appropriately estimating risk, there may be a role for emerging factors such as genetic polymorphism and dysfunctional HDL in assessing risk factors.

One traditional risk factor is particularly high in some Asian subgroups: smoking. Data from the California Health Interview Survey have provided the most complete picture of smoking prevalence estimates for Asian Americans and Asian-American subgroups. ${ }^{52}$ Korean Americans, Vietnamese Americans, and Filipino American males have some of the highest smoking rates, indicating the importance of having targeted interventions to address this cardiovascular risk factor for these subpopulations.

ACS affects a considerably larger proportion of South Asians than individuals from other Asian backgrounds. ${ }^{53}$ Significant differences have been noted in the overall risk factor dynamic of South Asians compared to non-South Asians who have suffered from acute MI compared to other races/ethnicities. Yet, despite this higher incidence of ACS in the South Asian population, the in-hospital case-fatality rate from actual MIs is not significantly different across groups ${ }^{53}$ It is also very important to look for nontraditional symptoms in certain Asian populations, including Chinese, South Asian, and Southeast Asian patients, who have been shown to be less likely to exhibit classic symptoms of acute MI. ${ }^{54}$ Southeast Asians also suffer from significant delays in recognizing symptoms and appropriate treatment: $30 \%$ of this minority group waited longer than 12 hours to seek treatment, whereas nonminorities were more likely to undergo treatment within 
3 hours of onset. ${ }^{54}$ After receipt of revascularization, South Asians have been shown to be less likely to experience longterm improvements in angina compared to whites. ${ }^{55}$

\section{Understanding communities}

Overall, minorities have an elevated risk of morbidity and mortality due to $\mathrm{CAD}^{56}$ and have not benefited to the same extent from the general decline in deaths caused by heart disease in the US over the last few decades. Population-level efforts to improve lifestyle interventions should be an important part of primary and secondary prevention strategies. Although the common wisdom may suggest that such interventions be universally applied, it must be noted that risk assessment is still a challenge in certain populations. For example, current guidelines used to identify metabolic syndrome underestimate the risk in South Asian individuals. ${ }^{57}$ Risk algorithms at the population level will need to be continually adjusted to account for these findings so they may more effectively assist in mitigating these disparities.

It is essential that health care providers understand the nuances in disease presentation, risk factors, and treatment in different racial and ethnic groups and communities. One strategy will be essential: cultural competency, which has been defined as the ability "to provide care to patients with diverse values, beliefs, and behaviors including tailoring delivery of care to meet patients' social, cultural, and linguistic needs." 58 Disparities are best addressed when all aspects of genetics and environment are considered.

A recent review on disparities in cardiovascular care found strong evidence for racial disparity in the use of diagnostic cardiac procedures, coronary revascularization, thrombolytic therapy, and other cardiac drug therapies, procedures, and treatments. ${ }^{36}$ Disparities in CAD treatment were shown to be at least partially mediated by the ways in which patients' races or ethnicity influenced physicians' perceptions of patients' social and behavioral characteristics. ${ }^{20}$ Awareness of these perceptions as well as differences in incidence, risk factor burdens, prognosis and treatment are necessary to mitigate racial and ethnic disparity.

Additional research and research strategies in minority communities can provide an opportunity to improve health disparities in CVD. Community-based participatory research, as well as intervention strategies that are community-generated, provide a powerful means for developing capacity at the local level. Such research can effectively evaluate not just whether a particular strategy worked, but for whom it worked and in what way. Collaborative interdisciplinary research offers a lens to see the complex interaction of the multifaceted issues related to health disparities (eg, personal, provider, and systems levels). This type of research, collaborative interdisciplinary research, demands input, coordination, and cooperation at a variety of levels (from communities to academia) to identify and implement successful solutions.

\section{Conclusion}

Decreasing health disparities must be a significant goal at the patient, provider, and systems levels. ${ }^{2}$ Although additional research is needed to fully understand the differences in CVD risk, prevention, and treatment to improve outcomes throughout our increasingly diversified population, greater awareness on the parts of practicing physicians is essential. Better understanding of the disparities of CVD risk factors may help clinicians and public health professionals develop culturally sensitive interventions, prevention programs, and services specifically targeted at risk burdens in each of these impacted populations. ${ }^{6}$ Burgeoning populations such as Hispanics and Asians should be incorporated into future research to help us better understand their CVD presentation and optimal interventions.

Eliminating disparities will require aggressive efforts focused on risk assessment, guideline adherence, and riskfactor control in at-risk populations. ${ }^{4}$

\section{Disclosure}

The author reports no conflicts of interest in this work.

\section{References}

1. US Census Bureau. An older and more diverse nation by midcentury [webpage on the Internet]. Washington, DC: US Census Bureau; 2008. Available from: http://web.archive.org/web/20080822044429/http://www. census.gov/Press-Release/www/releases/archives/population/012496. html. Accessed July 18, 2011.

2. Lurie N, Fremont A, Jain AK, et al. Racial and ethnic disparities in care: the perspectives of cardiologists. Circulation. 2005;111(10):1264-1269.

3. Nasir K, Shaw LJ, Liu ST, et al. Ethnic differences in the prognostic value of coronary artery calcification for all-cause mortality. $\mathrm{J} \mathrm{Am} \mathrm{Coll}$ Cardiol. 2007;50(10):953-960.

4. Watkins LO. Epidemiology and burden of cardiovascular disease. Clin Cardiol. 2004;27(6 Suppl 3):III2-III6.

5. Yeo K, Li Z, Amsterdam EA. Clinical characteristics and operative mortality among Whites, Hispanics, Asians and Blacks in the 2003 California Coronary Artery Bypass Graft Surgery Outcomes Reporting Program [Abstract 3117]. Circulation. 2006;114: II_658.

6. Kurian AK, Cardarelli KM. Racial and ethnic differences in cardiovascular disease risk factors: a systematic review. Ethn Dis. 2007;17(1): 143-152.

7. Bonow RO, Grant AO, Jacobs AK. The cardiovascular state of the union: confronting healthcare disparities. Circulation. 2005;111(10): 1205-1207.

8. Mensah GA, Mokdad AH, Ford ES, Greenlund KJ, Croft JB. State of disparities in cardiovascular health in the United States. Circulation. 2005;111(10):1233-1241.

9. Roger VL, Go AS, Lloyd-Jones DM, et al. American Heart Association Statistics Committee and Stroke Statistics Subcommittee. Executive summary: heart disease and stroke statistics - 2011 update: a report from the American Heart Association. Circulation. 2011;123:459-463. 
10. Wyatt SB, Williams DR, Calvin R, Henderson FC, Walker ER, Winters K. Racism and cardiovascular disease in African Americans. Am J Med Sci. 2003;325(6):315-331.

11. Ong KL, Cheung BM, Man YB, Lau CP, Lam KS. Prevalence, awareness, treatment, and control of hypertension among United States adults 1999-2004. Hypertension. 2007;49(1):69-75.

12. Redmond N, Baer HJ, Hicks LS. Health behaviors and racial disparity in blood pressure control in the national health and nutrition examination survey. Hypertension. 2011;57(3):383-389.

13. Kidambi S, Kotchen JM, Grim CE, et al. Association of adrenal steroids with hypertension and the metabolic syndrome in blacks. Hypertension. 2007;49(3):704-711

14. Bibbins-Domingo K, Gupta R, Na B, Wu AH, Schiller NB, Whooley MA. $\mathrm{N}$-terminal fragment of the prohormone brain-type natriuretic peptide (NT-proBNP), cardiovascular events, and mortality in patients with stable coronary heart disease. JAMA. 2007;297(2):169-176.

15. Astor BC, Yi S, Hiremath L, et al. N-terminal prohormone brain natriuretic peptide as a predictor of cardiovascular disease and mortality in blacks with hypertensive kidney disease: the African American Study of Kidney Disease and Hypertension (AASK). Circulation. 2008;117(13):1685-1692.

16. Kaul P, Lytle BL, Spertus JA, DeLong ER, Peterson ED. Influence of racial disparities in procedure use on functional status outcomes among patients with coronary artery disease. Circulation. 2005;111(10): 1284-1290.

17. Shaw LJ, Shaw RE, Merz CN, et al; American College of Cardiology-National Cardiovascular Data Registry Investigators. Impact of ethnicity and gender differences on angiographic coronary artery disease prevalence and in-hospital mortality in the American College of Cardiology-National Cardiovascular Data Registry. Circulation. 2008;117(14):1787-1801.

18. McSweeney JC, O'Sullivan P, Cody M, et al. Black, Hispanic, and White women's symptoms of coronary heart disease [Abstract 3306]. Circulation. 2006;114(Suppl):II_702.

19. Finkelstein EA, Khavjou OA, Mobley LR, Haney DM, Will JC. Racial/ethnic disparities in coronary heart disease risk factors among WISEWOMAN enrollees. $J$ Womens Health (Larchmt). 2004;13(5): 503-518.

20. van Ryn M, Burgess D, Malat J, Griffin J. Physicians' perceptions of patients' social and behavioral characteristics and race disparities in treatment recommendations for men with coronary artery disease. Am J Public Health. 2006;96(2):351-357.

21. Slater J, Selzer F, Dorbala S, et al. Ethnic differences in the presentation, treatment strategy, and outcomes of percutaneous coronary intervention (a report from the National Heart, Lung, and Blood Institute Dynamic Registry). Am J Cardiol. 2003;92(7):773-778.

22. Popescu I, Cram P, Vaughan-Sarrazin MS. Differences in admitting hospital characteristics for black and white Medicare beneficiaries with acute myocardial infarction. Circulation. 2011;123(23): 2710-2716.

23. Bahrami H, Kronmal R, Bluemke DA, et al. Differences in the incidence of congestive heart failure by ethnicity: the multi-ethnic study of atherosclerosis. Arch Intern Med. 2008;168(19):2138-2145.

24. Franciosa JA, Taylor AL, Cohn JN, et al; A-HeFT Investigators. African-American Heart Failure Trial (A-HeFT): rationale, design, and methodology. J Card Fail. 2002;8(3):128-135.

25. Taylor AL, Ziesche S, Yancy CW, et al; African-American Heart Failure Trial Investigators. Early and sustained benefit on eventfree survival and heart failure hospitalization from fixed-dose combination of isosorbide dinitrate/hydralazine: consistency across subgroups in the African-American Heart Failure Trial. Circulation. 2007;115(13):1747-1753

26. Melenovsky V, Borlaug BA, Rosen B, et al. Cardiovascular features of heart failure with preserved ejection fraction versus nonfailing hypertensive left ventricular hypertrophy in the urban Baltimore community: the role of atrial remodeling/dysfunction. $J$ Am Coll Cardiol. 2007;49(2):198-207.

27. Gillum RF. Stroke in blacks. Stroke. 1988;19(1):1-9.
28. Kleindorfer DO, Khoury J, Moomaw CJ, et al. Stroke incidence is decreasing in whites but not in blacks: a population-based estimate of temporal trends in stroke incidence from the Greater Cincinnati/Northern Kentucky Stroke Study. Stroke. 2010;41(7): $1326-1331$.

29. Bravata DM, Wells CK, Gulanski B, et al. Racial disparities in stroke risk factors: the impact of socioeconomic status. Stroke. 2005;36(7): $1507-1511$.

30. Ferris A, Robertson RM, Fabunmi R, Mosca L; American Heart Association; American Stroke Association. American Heart Association and American Stroke Association national survey of stroke risk awareness among women. Circulation. 2005;111(10): 1321-1326.

31. Howard G, Prineas R, Moy C, et al. Racial and geographic differences in awareness, treatment, and control of hypertension: the REasons for Geographic And Racial Differences in Stroke study. Stroke. 2006;37(5): 1171-1178.

32. Mitchell BD, Stern MP, Haffner SM, Hazuda HP, Patterson JK. Risk factors for cardiovascular mortality in Mexican Americans and non-Hispanic whites. San Antonio Heart Study. Am J Epidemiol. 1990;131(3):423-433.

33. Liao Y, Cooper RS, Cao G, Kaufman JS, Long AE, McGee DL. Mortality from coronary heart disease and cardiovascular disease among adult US. Hispanics: findings from the National Health Interview Survey (1986 to 1994). J Am Coll Cardiol. 1997;30(5):1200-1205.

34. Allison MA, Budoff MJ, Wong ND, Blumenthal RS, Schreiner PJ, Criqui MH. Prevalence of and risk factors for subclinical cardiovascular disease in selected US Hispanic ethnic groups: the Multi-Ethnic Study of Atherosclerosis. Am J Epidemiol. 2008;167(8):962-969.

35. Carnethon MR, Gulati M, Greenland P. Prevalence and cardiovascular disease correlates of low cardiorespiratory fitness in adolescents and adults. JAMA. 2005;294(23):2981-2988.

36. Kaiser Family Foundation. Racial/ethnic differences in cardiac care: the weight of the evidence [webpage on the Internet]. Menlo Park, CA: Kaiser Family Foundation; 2002. Available from: http://kff.org/ disparities-policy/fact-sheet/racialethnic-differences-in-cardiac-carethe-weight/.

37. Haffner SM, Stern MP, Hazuda HP, Rosenthal M, Knapp JA. The role of behavioral variables and fat patterning in explaining ethnic differences in serum lipids and lipoproteins. Am J Epidemiol. 1986;123(5): 830-839.

38. Bild DE, Detrano R, Peterson D, et al. Ethnic differences in coronary calcification: the Multi-Ethnic Study of Atherosclerosis (MESA) Circulation. 2005;111(10):1313-1320.

39. Reaven PD, Thurmond D, Domb A, Gerkin R, Budoff MJ, Goldman S. Comparison of frequency of coronary artery calcium in healthy Hispanic versus non-Hispanic white men by electron beam computed tomography. Am J Cardiol. 2003;92(10):1198-1200.

40. Morales LS, Leng M, Escarce JJ. Risk of cardiovascular disease in first and second generation Mexican-Americans. J Immigr Minor Health. 2011;13(1):61-68.

41. Ford ES, Giles WH, Dietz WH. Prevalence of the metabolic syndrome among US adults: findings from the third National Health and Nutrition Examination Survey. JAMA. 2002;287(3):356-359.

42. Ingelsson E, Arnlöv J, Lind L, Sundström J. Metabolic syndrome and risk for heart failure in middle-aged men. Heart. 2006;92(10):1409-1413.

43. Parikh SV, Enriquez JR, Selzer F, et al. Association of a unique cardiovascular risk profile with outcomes in Hispanic patients referred for PCI: results from the NHLBI Dynamic Registry [Abstract 916]. Circulation. 2008;118: S_632.

44. Riegel B, Carlson B, Romero T. Designing disease management programs for Hispanics with heart failure [Abstract 2508]. Circulation. 2007;114:II_517-II_518.

45. Ueshima H, Sekikawa A, Miura K, et al. Cardiovascular disease and risk factors in Asia: a selected review. Circulation. 2008;118(25): $2702-2709$. 
46. Palaniappan LP, Araneta MR, Assimes TL, et al; American Heart Association Council on Epidemiology and Prevention; American Heart Association Council on Peripheral Vascular Disease; American Heart Association Council on Nutrition, Physical Activity, and Metabolism; American Heart Association Council on Clinical Cardiology; American Heart Association Council on Cardiovascular Nursing; Council on Cardiovascular Nursing. Call to action: cardiovascular disease in Asian Americans: a science advisory from the American Heart Association. Circulation. 2010;122(12):1242-1252.

47. Ajjan R, Carter AM, Somani R, Kain K, Grant PJ. Ethnic differences in cardiovascular risk factors in healthy Caucasian and South Asian individuals with the metabolic syndrome. JThromb Haemost. 2007;5(4): 754-760.

48. Heald AH, Anderson SG, Ivison F, Laing I, Gibson JM, Cruickshank K. C-reactive protein and the insulin-like growth factor (IGF)-system in relation to risk of cardiovascular disease in different ethnic groups. Atherosclerosis. 2003;170(1):79-86.

49. Bartys S, Baker D, Lewis P, Middleton E. Inequity in recording of risk in a local population-based screening programme for cardiovascular disease. Eur J Cardiovasc Prev Rehabil. 2005;12(1):63-67.

50. D’Agostino RB, Grundy S, Sullivan LM, Wilson P; CHD Risk Prediction Group. Validation of the Framingham coronary heart disease prediction scores: results of a multiple ethnic groups investigation. JAMA. 2001;286(2):180-187.

51. Aarabi M, Jackson PR. Predicting coronary risk in UK South Asians: an adjustment method for Framingham-based tools. Eur J Cardiovasc Prev Rehabil. 2005;12(1):46-51.
52. Tang H, Shimizu R, Chen MS. English language proficiency and smoking prevalence among California's Asian Americans. Cancer. 2005;104(Suppl 12):2982-2988.

53. Gupta M, Doobay AV, Singh N, et al. Risk factors, hospital management and outcomes after acute myocardial infarction in South Asian Canadians and matched control subjects. CMAJ. 2002;166(6):717-722.

54. King KM, Khan NA, Quan H. Ethnic variation in acute myocardial infarction presentation and access to care. Am J Cardiol. 2009;103(10): 1368-1373.

55. Zaman MJ, Crook AM, Junghans C, et al. Ethnic differences in longterm improvement of angina following revascularization or medical management: a comparison between south Asians and white Europeans. J Public Health (Oxf). 2009;31(1):168-174.

56. Chaturvedi N. Ethnic differences in cardiovascular disease. Heart. 2003;89(6):681-686.

57. Eapen D, Kalra GL, Merchant N, Arora A, Khan BV. Metabolic syndrome and cardiovascular disease in South Asians. Vasc Health Risk Manag. 2009;5:731-743.

58. Yancy CW, Wang TY, Ventura HO, et al; credo Advisory Group. The coalition to reduce racial and ethnic disparities in cardiovascular disease outcomes (credo): why credo matters to cardiologists. J Am Coll Cardiol. 2011;57(3):245-252.

59. LaViest T, Gaskin D, and Richard P. The Economic Burden of Health Inequalities in the United States, 2009. Report commissioned by the Joint Center for Political and Economic Studies.

60. Davis AM, Vinci LM, Okwuosa TM, Chase AR, Huang ES. Cardiovascular health disparities: a systematic review of health care interventions. Med Care Res Rev. 2007;64(5 Suppl):29S-100S.
International Journal of General Medicine

\section{Publish your work in this journal}

The International Journal of General Medicine is an international, peer-reviewed open-access journal that focuses on general and internal medicine, pathogenesis, epidemiology, diagnosis, monitoring and treatment protocols. The journal is characterized by the rapid reporting of reviews, original research and clinical studies across all disease areas.

\section{Dovepress}

A key focus is the elucidation of disease processes and management protocols resulting in improved outcomes for the patient. The manuscript management system is completely online and includes a very quick and fair peer-review system. Visit http://www.dovepress.com/ testimonials.php to read real quotes from published authors. 